\title{
Scanning Electron Microscopy Images of Moistened Wheat Grains: Frictional Properties
}

\author{
Fatih Kalkan ${ }^{1}$ and Arkom Palamanit ${ }^{2}$
}

\begin{abstract}
In this study, grains of two wheat cultivars namely Eser and Fuatbey-2000 were moistened and then their surface physical structures were observed via scanning electron microscopy (SEM) images. The moisture content levels were 8.09, 16.59, 23.85 and 35.63 (\% d.b.) for Eser grains and were 7.71, 15.79, 23.59 and 34.90 (\% d.b.) for Fuatbey-2000 grains. The images obtained from SEM indicated that not only the surfaces of cultivars were structurally difference from each other, but also surface structures of cultivars were visibly changed at different moisture content levels.
\end{abstract}

Keywords-Moisture content, Scanning electron microscopy, Surface structure, Wheat

\section{INTRODUCTION}

$\mathrm{W}$ HEAT production was $729,012,175$ tons, making it the second most-produced cereal in the world subsequent to the maize production with $1,037,791,518$ tons while wheat production was the first $19,000,000$ tons in Turkey (FAO, 2014).

Physical properties of agricultural products which physically identify the products are important to design and develop the proper machines during harvesting and post harvesting processing and to build storage structures. The frictional properties are precious knowledge in predicting the pressure of agricultural granular products against bin walls, silos and the storage structures. It is also fundamental knowledge in order to design the conveyors because friction is needed to hold the granular products to the conveying surface without sliding backward. In addition, the static coefficient of friction between agricultural products and conveyor belt affects the maximum angle with the horizontal that the conveyor can assume when transporting the agricultural products.

There have been carried out several reported works in the literature on the frictional properties of cereal products depending on moisture content. Baryeh (2002) investigated the physical properties of millet grains. The author reported that static coefficient of friction and angle of repose of millet grains increased with increase in moisture content because the grains became rougher and sliding characteristics were diminished. While the static coefficient of friction that was

Fatih kalkan ${ }^{1}$, was with the Yuzuncu Yil University, Agriculture Faculty, Department of Biosystem Engineering, Van, 65080, Turkey (corresponding author's phone: +90 5362720071; e-mail: fatihkalkan0017@ hotmail.com).

Arkom Palamanit ${ }^{2}$, was with Energy Systems Research Institute, Prince of Songkla University, 15 Karnjanavanich Rd., Hat Yai, Songkhla, 90110, Thailand (e-mail: energy_man001@hotmail.com). determined for three different surfaces by the author was the lowest for galvanized iron, it was the highest for plywood. Tabatabaeefar (2003), who evaluated the physical properties of some wheat grains as a function of moisture content. The static coefficient of friction and the angle of repose of wheat grains increased with increase in moisture content on all frictional surfaces. The author was also reported that the moisture content had more effect than did the material's surface on the static coefficient of friction due to the increase of adhesion at higher moisture levels. Coşkun et al. (2006), while evaluating physical properties of sweet corn seed, concluded that static coefficient of friction values varied from surface to surface and increased as the moisture content increased for all the friction surfaces. Those values were maximum with respect to rubber and minimum with respect to stainless steel. In the study carried out by Al-Mahasneh and Rababah (2007) was researched the effect of moisture content on physical properties of green wheat grains. The static coefficient of friction that increased with increase in moisture content was obtained the highest for plywood. The authors reported that the trend could be explained by plywood surface of which was rougher compared to the other tested surfaces. A study at which physical properties of wheat grains as a function of moisture content were determined was carried out by Karimi et al. (2009). The author reported that the static coefficient of friction and the angle of repose of some wheat cultivars increased when the moisture content increased and the highest static coefficient of friction was obtained on compressed plastic. Kalkan and Kara, (2011) and Kalkan et al. (2011) were determined the angle of repose of some wheat cultivars and popcorn respectively as a function of moisture content. The authors reported that the angle of repose of these products increased with increase in moisture content.

Although surface structures of agricultural products were adverted in the studies above-mentioned to be able to explain the change of frictional properties of agricultural products depending on the moisture content, information on the surface structure of agricultural products is missing in the literatures. Therefore, this study was to contribute to fill in this gap.

\section{MATERIAL AND METHODS}

Cvs. Eser and Fuatbey-2000 grains were used for test material. The wheat cultivars were obtained from different sources: cv. 'Eser' from the Crop Plants Central Research Institute, Ankara (central part of Turkey) and cv. Fuatbey- 
2000 from the Trakya Agricultural Research Institute, Edirne (northwest part of Turkey).

The initial moisture content of the grains was determined by the standard oven drying method at $105{ }^{\circ} \mathrm{C}$ for $24 \mathrm{~h}$ (Suthar and Das, 1996). The grains were wetted in order to obtain moisture contents of 8.09 to $35.63 \%$ d.b. for cv. Eser grains and 7.71 to $34.90 \%$ d.b. for cv. Fuatbey-2000 grains. To get the desired moisture contents for higher levels, a certain amount of water calculated using the following equation was added to samples in glass jar:

$M_{w}=\frac{M_{i}\left(M_{f}-M_{i}\right)}{100-M_{f}}$

Where $M_{w}$ is the mass of water added to sample in $\mathrm{kg}, M_{i}$ is initial moisture content of sample in \% d.b, $M_{f}$ is final moisture content of sample in \% d.b.

Then the moist grain samples were sealed thoroughly in separate glass jars, mixed and kept in a refrigerator at $5{ }^{\circ} \mathrm{C}$ for 7 days to ensure the moisture to distribute uniformly throughout the grains. Also, the moisture contents of grain samples were checked just before SEM examinations.

๑Cv. Eser Cv. Fuatbey-2000

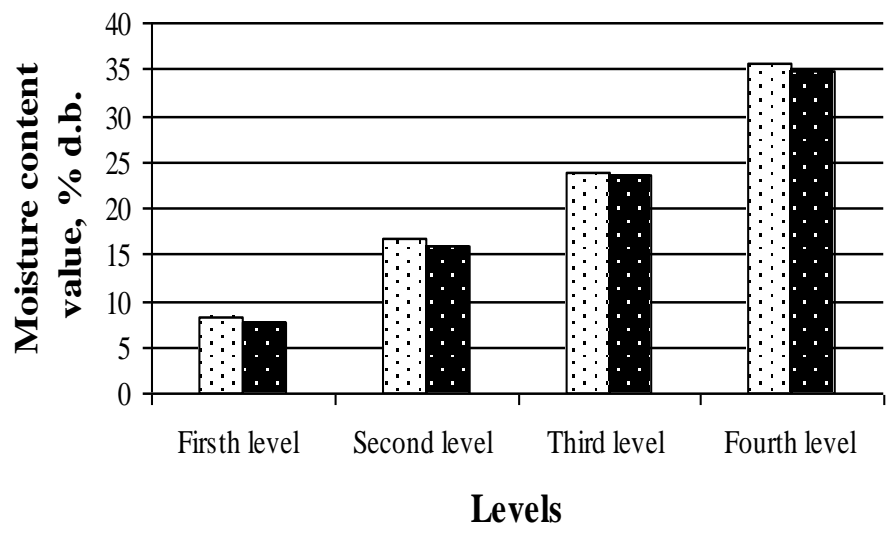

Fig. 1. Selected moisture content levels of wheat grains, $\%$ d.b.

Scanning electron microscopy images were taken at the Scanning Electron Microscopy (SEM) Laboratory in Department of Metallurgical and Materials Engineering of Middle East Technical University (METU), Ankara, Turkey. Surfaces of wheat samples were examined using JEOL JSM6400 Scanning Electron Microscope. Before SEM examinations, the sample surfaces were coated with $20 \mathrm{~nm}$ of gold to obtain a conductive surface and to avoid electrostatic charging during examination. The SEM images were taken from three different grains for each cultivar. Moreover, it was selected different regions in each grain for image. One SEM images of grains were randomly put for the study.

\section{RESULTS AND DISCUSSIONS}

$\mathrm{S}$ URFACE structures of cvs. Eser and Fuatbey-2000 grains are presented in Fig.1 and 2 at different moisture content levels. As seen from the figures, not only surfaces of wheat cultivars were structurally difference from each other, but also surface structures of cultivars were visibly changed at further moisture content levels (Fig 1 and 2).

When the mentioned figures were investigated, it was seen that the surface structures of the cultivars had longitudinal parallel ridges to each other, which they were more apparent at the initial moisture content levels compared to the further moisture content levels (Fig. 1-A,B,C,D and 2-A,B,C,D). However, the surface structures of the cultivars gradually transformed into a relatively flat structure at further moisture content levels with swelling the gaps of ridges due to water absorption (Fig. 1-B,C,D and 2-B,C,D) and longitudinal parallel ridges became lesser apparent. This trend was observed more clearly in cv. Eser grains, which may be explained that cv. Eser grains are softer than cv. Fuatbey-2000 grains which are a durum wheat grains. At this point, if frictional properties of the cultivars on any frictional surface were considered, contact areas of the longitudinal parallel ridges on any frictional surface at the initial moisture content levels of cultivars were to be lower compared to the further moisture content levels and they were to increase with increase in moisture content level (Fig. 1-A,B,C,D and 2-A,B,C,D); thus, static and dynamic coefficients of friction and angle of repose were to increase. Likewise, in a previous study, Stewart et al. (1969) reported that both static and dynamic coefficients of friction increased with increase in moisture content level of the sorghum grains on the tested frictional surfaces, which might be caused by a larger contact area between the grain and test surfaces. In literature, some researchers have reported that static and dynamic coefficients of friction increased with increase in contact area of the grains on frictional surfaces at further moisture contents (Davies and El-Okene, 2009; Kalkan and Kara, 2011).

When the moisture content of agricultural products increases, the surface of the samples becomes more sticky (Aghajani, 2012). Likewise, it might be seen from the related figures that the surfaces of cvs. Eser and Fuatbey-2000 grains were structurally lesser lustrous at the further moisture content levels compared to the initial moisture content levels owing to the water present in the grains and it might be said that the cultivars has been more sticky at further moisture content levels. Likewise, water tends to adhere to surfaces and the water on the moistened seed surface would be attracted to the surface across which the sample is being moved and thus frictional properties would increase. 

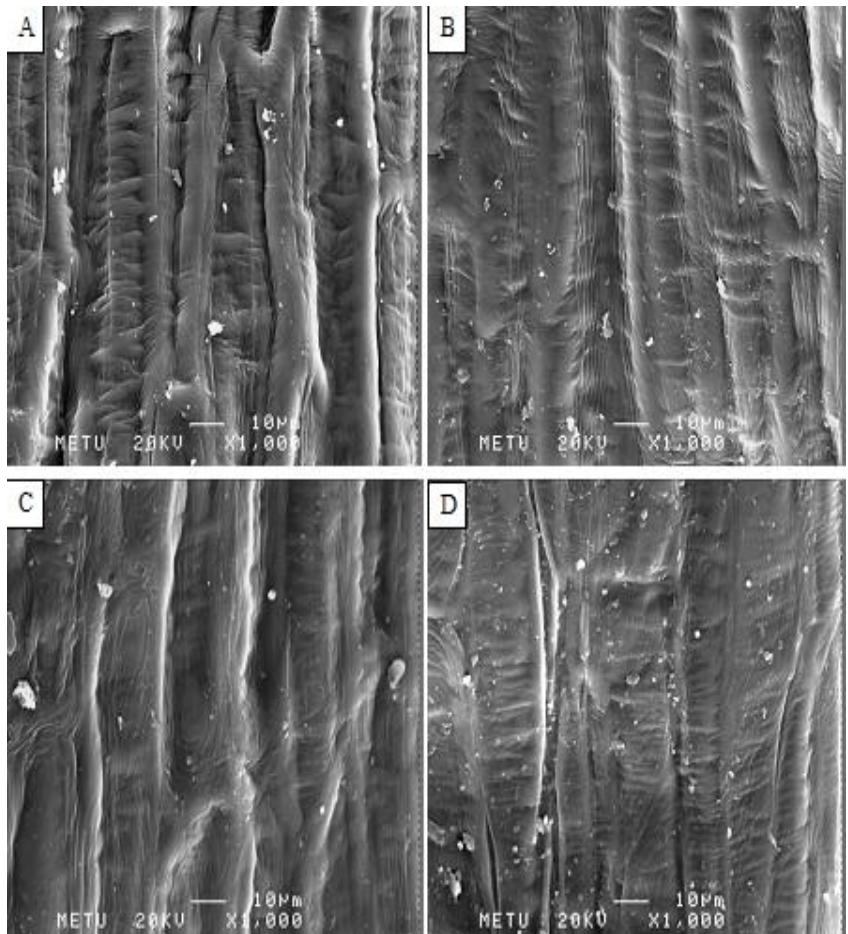

Fig.2. Effect of moisture content on surface structure of cv. Eser, A: Moisture content of $8.09 \%$ d.b., B: $16.59 \%$ d.b., C: $23.85 \%$ d.b., D: $35.63 \%$ d.b
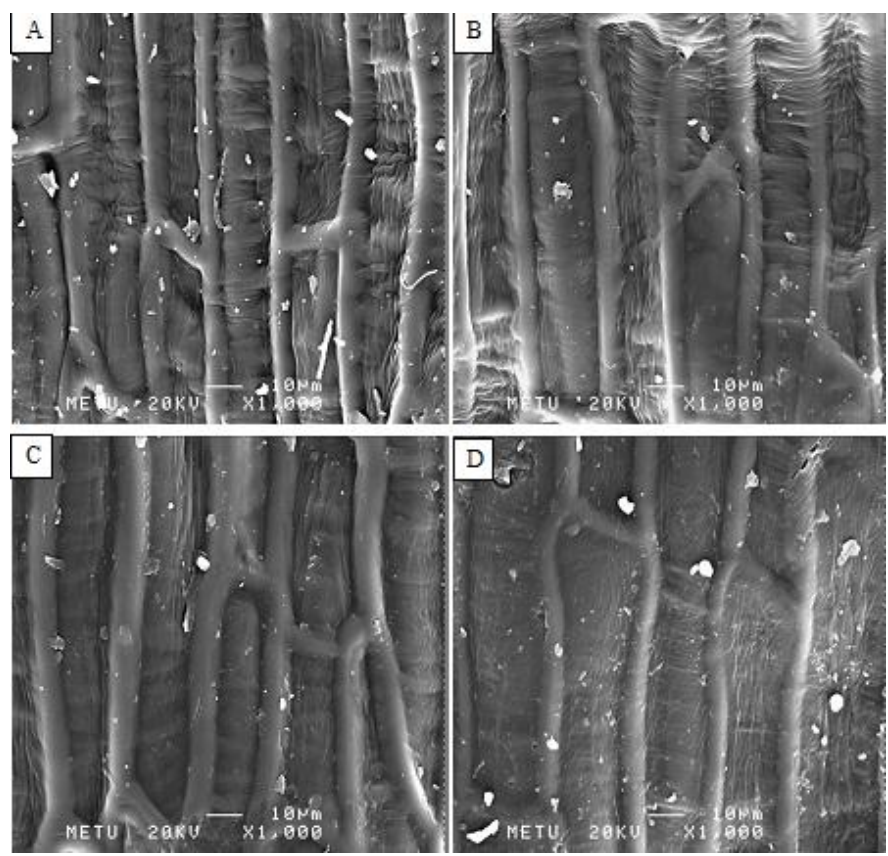

Fig.3. Effect of moisture content on surface structure of cv. Fuatbey-2000, A: Moisture content of $7.71 \%$ d.b., B:15.79\% d.b., C: $23.59 \%$ d.b., D: $34.90 \%$ d.b.

\section{CONCLUSION}

As seen from the scanning electron microscopy images, both surfaces structures of wheat cultivars were different from each other and surface structures of cultivars were visibly changed depending on moisture content levels.

\section{REFERENCES}

[1] Aghajani, N., Ansaripour, E., Kashaninejad, M., 2012. Effect of moisture content on physical properties of barley seeds. Journal of Agricultural Science and Technology, 14, 161-172.

[2] Al-Mahasneh, M.A., Rababah, T.M., 2007. Effect of moisture content on some physical properties of green gram. Journal of Food Engineering, 79, 1467-1473.

[3] Baryeh, E.A., 2002. Physical properties of millet. Journal of Food Enginnering, 51, 39-46.

[4] Coşkun, M.B., Yalçın, İ., Özarslan, C., 2006. Physical properties of sweet corn seed (Zea mays saccharata Sturt). Journal of Food Engineering, 74, 523-528.

[5] Davies, R.M., El-Okene, A.M., 2009. Moisture-dependent physical properties of soybeans. International Agrophysics, 23, 299-303.

[6] FAO, 2014. http://www.fao.org/ (27 $7^{\text {th }}$ March 2017).

[7] Kalkan, F., Kara, M., 2011. Handling, frictional and technological properties of wheat as affected by moisture content and cultivar. Powder Technology, 213(1-3), 116-122.

[8] Kalkan, F., Kara, M., Bastaban, S., Turgut, N., 2011. Strength and frictional properties of popcorn kernel as affected by moisture content. International Journal of Food Properties, 14(6), 1197-1207.

[9] Karimi, M., Kheiralipour, K., Tabatabaeefar, G.M., Khoubakht, M., Naderi, M., Heidarbeigi K., 2009. The effect of moisture content on physical properties of wheat. Pakistan Journal of Nutrition, 8(1), 9095.

[10] Stewart, B.R., Hossain, Q.A., Kunze, O.R., 1969. Friction coefficients of sorghum grain on steel, teflon and concrete surfaces. Transactions of The ASAE, 12(4), 415-418.

[11] Tabatabaeefar, A., 2003. Moisture-dependent physical properties of wheat. International Agrophysics, 17, 207-211.

[12] Suthar, S.H., Das, S.K., 1996. Some physical properties of karingda (Citrus lanatus (thumb) mansf) seeds. Journal of Agricultural Engineering Research, 65, 15-22. 